\title{
ESTÉTICA ILUSTRADA, DISCURSOS DE CLASE Y EDUCACIÓN MUSICAL ESCOLAR EN LOS COMIENZOS DEL SIGLO XX
}

\section{Illustrated aesthetic, class discourses and music education in schools in the early Twentieth century}

\author{
María Eugenia Bolaño Amigo* \\ Fecha de recepción: 07/06/2016 • Fecha de aceptación: 23/10/2016
}

Resumen. En torno a la idea de «música culta» giran representaciones, acentuadas desde la época renacentista, que condicionaron y condicionan los modos de educación musical, así como las construcciones socioculturales que de esta pueden derivarse. De esta forma, los discursos subyacentes a esta noción de «música» prevalecieron aún con las notables innovaciones introducidas a comienzos del siglo xx en el ámbito de la educación musical que, por otra parte, tuvieron sus principales repercusiones en las metodologías utilizadas en el aula de música. Atendiendo a estos aspectos, pretendemos ofrecer una aproximación a los procesos que, entre finales del siglo XIX y a comienzos del siglo XX, se inclinaron por amparar una idea de «música culta», con sus respectivas incidencias en la historia educativa escolar.

Palabras clave: Estética ilustrada; Discursos de clase; Educación musical escolar; Siglo Xx; «Música culta».

Abstract. The Concept of "serious music» has been subject to kinds of representations, especially since the Renaissance, which conditioned and continue to condition approaches to musical education as well as the socio-cultural constructions deriving from them. Thus, the underlying discourses regarding this notion of "music» still prevailed even with the notable innovations introduced in the early twentieth century in the area of music education, innovations which also had a major impact on the methodologies used in music class. Based on these considerations, we attempt to offer an approximation to the processes that, during the late nineteenth and early twentieth

\footnotetext{
" Departamento de Pedagoxía e Didáctica. Facultade de Ciencias da Educación. Universidade de Santiago de Compostela. Rúa de Vicente Fraiz Andón. Campus Vida. 15782 Santiago de Compostela. A Coruña. España. mariaugenia.bolano@usc.es
}

Cómo citar este artículo: Bolaño Amigo, María Eugenia. «Estética ilustrada, discursos de clase y educación musical escolar en los comienzos del siglo xx», Historia y Memoria de la Educación, 5 (2017): 385-400. 
centuries, tended to support the idea of "serious music» while we also examine the influence they had on school educational history.

Keywords: Illustrated aesthetic; Class discourses; School music education; Twentieth century; "Serious music».

\section{INTRODUCCIÓN}

El concepto de «música», como construcción sociocultural que es, varía en relación a las representaciones de cada grupo humano en contextos espaciales y temporales determinados. No existe, pues, una idea «universal» de música, ${ }^{1}$ aunque sí suele prevalecer entre nosotros la idea de «música» como el más universal de los lenguajes. ${ }^{2}$ Cuando hablamos de música aludimos, por lo tanto, a una multiplicidad y variedad de experiencias y de actividades. De este modo, podría resultar poco «ético» preservar la idea de que existe una música más «auténtica» o más «elevada» que otra, si bien en Occidente disponemos de fuentes que nos permiten afirmar que esta noción comienza a gestarse ya en el siglo $\mathrm{V}$ antes de nuestra era, ${ }^{3}$ y aún podríamos encontrar este planteamiento reproducido en civilizaciones más lejanas. Con todo, hoy en día seguimos sustentando y alimentando representaciones musicales - acarreando muchas veces los correspondientes valores que trasladan-que no son propias de nuestra época y contexto, sino que nos retrotraen a otros lugares y tiempos.

\footnotetext{
${ }^{1}$ En este sentido señala Nicholas Cook que la palabra «música» constituye un constructo que «adopta tantas formas como identidades culturales o sub-culturales existentes»; en Nicholas Cook, De Madonna al Canto Gregoriano. Una muy breve introducción a la música (Madrid: Alianza Editorial, 2001).

${ }^{2}$ Noción comprensible en el mundo occidental eurocéntrico que se torna más compleja si observamos la existencia de culturas que no disponen de una sola palabra para definir «música», sino que a esta vinculan múltiples experiencias asociadas que podrían englobar incluso a otras artes como la danza o el teatro; o si tenemos en cuenta a aquellas sociedades que no establecen distinciones entre la idea de «escuchar música» y «ser música o músico». Siendo así, posiblemente esta idea de la música como «lenguaje universal» se distorsiona, al apreciar que ante una misma interpretación musical las reacciones entre personas pertenecientes a distintos lugares y momentos históricos serían bien diferentes. Incluso podría decirse que bajo esta tesis subyacen intereses ligados a la imposición de «un tipo de música universal» que responda a criterios de valor de cambio y no de valor de uso (como sucede en sociedades precapitalistas), así como a las demandas de carácter mercantil o lucrativo del mundo capitalista en el que vivimos (así sucede, cada vez más, en este y otros ámbitos como el de la alimentación o el de la moda, entre otros).

${ }^{3}$ Remitiéndonos al descubrimiento del filósofo griego Pitágoras, conforme el cual las notas de la escala musical se corresponden con sencillas proporciones de números enteros. En esta línea, según especularon Pitágoras y sus seguidores, todo el universo estaría construido bajo los mismos principios matemáticos, de forma que la música que oímos sería una versión audible de la armonía que une los elementos del universo, la denominada «música de las esferas».
} 
Es en el período de la Ilustración, con su declarada intencionalidad de «disipar las tinieblas de la humanidad mediante el uso de la razón», cuando comienza a concebirse la cultura como un proceso de perfeccionamiento intelectual ligado a la formación del espíritu, asociándose igualmente a aquellas actividades tradicionalmente vinculadas a un estatus social elevado. Se supedita entonces el concepto de «cultura» al de «cultura de élite», ${ }^{4}$ y habrá que esperar prácticamente hasta finales del siglo XIX, con la aparición de voces que hablan de «cultura popular» y de "pluralidad de culturas» frente a los valores más elitistas y clasistas, para apreciar las reacciones ante esta concepción. Todos estos constructos se trasladan al ámbito de la cultura musical y de su enseñanza, donde hasta la fecha siguen prevaleciendo ideas conectadas con la representación ilustrada de «música culta» que trascienden a todos los ámbitos musicales.

Partiendo de estos preceptos y atendiendo a las indicaciones procedentes de la historia social, de la historia cultural, de la sociología de la música y de la historia de la estética musical, pretendemos aquí presentar un recorrido que nos aproxime a una mejor comprensión de algunos de los procesos que, en Europa y ya de desde finales del siglo XIX y comienzos del xx, optaron por preservar la idea de «música culta», con su consecuente incidencia en la historia educativa escolar, escapando así a otras posibilidades de educación musical.

En este sentido, en un primer momento nos centraremos en indagar en torno a las recíprocas influencias existentes entre ideologías, clases sociales y las formas de concebir y/o hacer música. Esto nos permitirá acercarnos, de un modo más crítico y comprensivo, a los discursos que, a comienzos del siglo xx y con dispares incidencias, han podido estar presentes en la educación musical escolar. Finalmente, concluiremos el trabajo perfilando posibles horizontes para la educación musical escolar en nuestros días.

\footnotetext{
${ }^{4}$ La conceptualización de «estética ilustrada», aplicada a la música, apela a la dimensión cultural de este arte como «cultura de élites». Esta visión remite a una concepción de «cultura» restringida y asociada a determinados grupos sociales, de manera que estaría enmarcada en la denominada «perspectiva humanista o ilustrada». Dicha perspectiva se construye como una noción jerárquica mediante la cual se procede a la estratificación de los diversos segmentos sociales atendiendo a la distribución de los bienes culturales o simbólicos. Este concepto sería opuesto a la «perspectiva romántico-antropológica», que comprendería todas las expresiones materiales y simbólicas de un grupo humano.
} 


\section{IDEOLOGÍAS, CUESTIONES DE CLASE Y MÚSICA: INFLUENCIAS RECÍPROCAS $^{5}$}

La distinción entre las concepciones occidentales de «música culta» y «música popular» es heredera de la diferenciación entre «cultura de élites» y «cultura popular», que se fue acentuando paulatinamente desde los comienzos del Renacimiento y desde sus expresiones cortesanas. Efectuando un muy breve recorrido en torno a esta evolución podemos aludir a que el siglo XVI se configura como una época de fuerte expresividad de la cultura popular. Además, la relación entre ésta y la cultura de élites parece ser estrecha "aunque planteada de forma asimétrica». ${ }^{6}$ Sin embargo, en el siglo siguiente, debido fundamentalmente a algunas de las consecuencias de las reformas religiosas, ${ }^{7}$ la presencia tolerada o legitimada de la cultura popular, casi siempre expresión de libertad y de crítica de órdenes estereotipados, retrocede. La brecha entre «alta» y «baja» cultura será aún mayor a medida que avanza el siglo XVIII, desde el momento en que los sectores nobiliarios y de la alta burguesía renuncian a participar en la cultura popular, marcando la diferencia y ocasionando con ello el oscurecimiento de tantos aspectos de la cultura popular. No será hasta bien entrado el siglo XIX cuando se redescubren, bajo algunas influencias del romanticismo estético, formas propias de la cultura popular que comienzan a incidir en las artes, abriéndose entonces un diálogo entre la cultura tradicional popular y la «alta cultura», lo que atañe también al campo musical. No obstante, la consolidación de los sectores sociales burgueses interesados en preservar esa idea de cultura $-\mathrm{y}$ por extensión, de música «por y para» élites- generará espacios y modos de hacer destinados a tal fin, en muchos casos «exclusivos» y/o «excluyentes».

Es precisamente a lo largo del siglo XIX cuando aparecen instituciones e industrias que centran su labor en el desarrollo de funciones comerciales ligadas a la música. Además, se introducen en este tiempo cambios en la forma de crear y de percibir música que van paulatinamente in-

\footnotetext{
${ }^{5}$ Para la elaboración de este epígrafe nos hemos apoyado fundamentalmente en María Eugenia Bolaño Amigo, «Estética ilustrada musical e intereses ideológicos. Preservación de la idea de música culta a comienzos del siglo Xx, clases sociales y educación», en Actas del XVIII Coloquio de Historia de la Educación. Arte, literatura y educación, ed. Núria Padrós, Eulàlia Collelldemont y Joan Soler (Vic: Universitat de Vic-Universitat Central de Catalunya, 2015).

${ }^{6}$ Jaime Hormigos Ruiz, Música y sociedad. Análisis sociológico de la cultura musical de la posmodernidad (Madrid: Fundación Autor, 2008), 124.

${ }^{7}$ Pues tanto la reforma protestante como la católica tacharon a la cultura popular de «pagana e inmoral».
} 
crementándose hasta configurar el amplio y diverso panorama musical que durante todo el siglo xx se fue enriqueciendo. En este sentido, el escritor italiano Baricco $^{8}$ asume que esta industria cultural, que paulatinamente va surgiendo a partir del siglo XIX, es la misma que moldea segmentos diferenciales de mercado, bajo sus propios códigos, que se encuentran arraigados en los iconos decimonónicos, perfilando así la división de los consumidores. ${ }^{9}$ Una segmentación que concede una supuesta mayor relevancia, complejidad, superior articulación y huella cultural a la denominada «música culta». Estas argumentaciones, que emanan de la preconcepción «de que la música es una especie de ventana abierta a un mundo esotérico que está más allá del conocimiento ordinario» ${ }^{10}$ ya presente en civilizaciones ancestrales, ${ }^{11}$ fueron además consolidadas en el Romanticismo más incipiente con la figura de Ludwig van Beethoven (1770, Bonn, Alemania - 1827, Viena, Austria). De esta manera, se le otorgaban a la música tradicionalmente designada como «clásica» significados espirituales y filosóficos, que incluso llevaban al músico - y prioritariamente, al considerado «músico por excelencia», el compositor- a escapar de la óptica comercial de su trabajo; asimismo, se consideraba que esta música lograba en cuanto a su gramática y sintaxis musical una complejidad superior que, por ello, desafiaba las capacidades receptivas de un público «normal», tornándose entonces solo apta para oyentes «expertos» o "entendidos», siendo esta visión ideológica la que se traslada desde las concepciones de la burguesía romántica hasta nuestros días.

En este sentido, hoy sabemos que la música, posiblemente debido a su amplia capacidad comunicativa, ha sido utilizada en todas las épocas y contextos de Occidente para «legitimar racionalmente un orden social,

\footnotetext{
${ }^{8}$ Alessandro Baricco, El alma de Hegel y las vacas de Wisconsin (Madrid: Siruela, 1999).

${ }^{9}$ Una división que nos remite a atender las tesis reflejadas en 1979 por Bourdieu en La distinción, según las cuales el capital cultural de las clases dominantes ejercería una «violencia simbólica» sobre las clases dominadas, de modo que, entiende Bourdieu, «la estética de la clase trabajadora es una estética dominada, a la que se obliga a definirse siempre en términos de la estética dominante». En Pierre Bourdieu, Distinction: A social critique of the judgement of taste (Cambridge: Harvard University Press, 1984), 41.

${ }^{10}$ Cook, De Madonna al Canto Gregoriano, 57.

${ }^{11}$ Escritores como el alemán E. T. A. Hoffmann (1776-1822) recordaron estas antiguas civilizaciones al aludir a la música como «el reino del espíritu».
} 
que es, en definitiva, el objetivo de la ideología». ${ }^{12}$ Dentro de este orden de ideas, actualmente disponemos de variados trabajos que focalizan su atención en el alcance de la música para transmitir determinadas ideologías al servicio de intereses políticos y morales. Se trata de estudios centrados especialmente en períodos históricos o en compositores concretos, enfocados desde muy diversas perspectivas. ${ }^{13}$ Tomándolos en consideración podemos afirmar que el lenguaje musical y, con él, toda clase de prácticas ligadas a la música, no son neutras. Bajo el velo de la obra artística subyacen imágenes y representaciones sociales que son transmitidas y sobre las cuales elaboramos, divulgamos y/o asumimos —de forma más o menos consciente- categorías y sistemas de valores. ${ }^{14}$

Estas representaciones sociales de las que hablamos han sido utilizadas a lo largo de la historia para diferenciar «tipologías musicales» y vincular las mismas a distintos grupos sociales. ${ }^{15} \mathrm{Y}$ esto es así porque «encontramos en la música una síntesis de los procesos cognitivos propios de una cultura y, también, del resultado de sus interacciones sociales», ${ }^{16}$ siendo conscientes de que:

La expresión musical es una constante en la especie humana y, entendiéndola de este modo, hay algunos elementos y compor-

\footnotetext{
${ }^{12}$ Horacio Capel, José María López y José Tomás Pardo, Ciencia e ideología en la ciudad (vol. II). I Coloquio interdepartamental (Valencia: Generalitat valenciana, Conselleria d'Obres Públiques, Urbanisme i Transports, 1992), 139.

${ }^{13}$ Entre ellos podemos destacar los comprendidos en la obra de Theodor Wiesengrund Adorno (19031969), pues como bien señala Fubini «para valorar en plenitud la importancia histórica de su extensa obra hace falta previamente valorar el hecho de que ningún musicólogo había intentado jamás captar, con tanta profundidad y agudeza como lo hizo él, los nexos que ligan estrecha y dialécticamente la música con el mundo de la ideología»; en Enrico Fubini, La estética musical desde la Antigüedad hasta el siglo XIX (Madrid: Editorial Alianza Música, 2010), 437. Comprendemos pues que, a pesar de las críticas que su pensamiento haya podido recibir, actualmente resulta difícil proyectar una mirada alrededor de la problemática ideológica, filosófica y estética que gira en torno a la música del siglo $\mathrm{XX}$ sin tener presentes sus tesis.

${ }^{14}$ Efectuamos esta afirmación siendo conscientes de que los propios músicos (intérpretes y compositores) evitaron después de la Segunda Guerra Mundial el sometimiento de su creación artística a la instrumentalización política, aunque no siempre fue posible. Muchos otros músicos fueron conscientes del papel que la música podía desempeñar como transmisora de ideas y procedieron a su utilización apoyando determinadas ideologías o concepciones políticas y sociales de su tiempo.

${ }^{15}$ Es del caso aludir, como ejemplo, a la parcela musical conocida como «Gran Música», dirigida a públicos de la burguesía supuestamente cultos; al Canto Coral, vehículo de ideas moralizadoras destinado a clases medias, o a la Zarzuela, expresión o representación de segmentos sociales populares españoles (Capel, López y Pardo, Ciencia e ideología en la ciudad, 1.
}

${ }^{16}$ Hormigos Ruiz, Música y sociedad, 20. 
tamientos universales en ella. Ahora bien, una determinada música sólo puede entenderse en un contexto social que le confiere un valor y que genera un abanico de emociones inseparables de las vinculaciones sociales [...]. Ningún estilo musical se construye con características exclusivas, [pues] sus dimensiones son las que quiera darle su sociedad y su cultura. ${ }^{17}$

Acudiendo a palabras de Dufour, podríamos añadir aún que es imposible atribuir un fenómeno estético simplemente a sus orígenes sociales, pero tampoco podremos conocerlo en todas sus dimensiones si no indagamos en sus condicionantes sociohistóricos, pues son estos los que contribuyen a «arrojar luz y sentido sobre los motivos - conscientes o inconscientes - que le dieron sentido, y abrir posibles vías reflexivas sobre la renovación de los términos de esa experiencia estética». ${ }^{18}$

A pesar de lo dicho, no debemos eludir, sin embargo, que durante el siglo XIX y comienzos del XX, existieron diversos escritores y compositores que reivindicaron la trascendencia de la música clásica como arte autónomo con respecto a las ideologías y a la política y que, por lo tanto, esta debía componerse, interpretarse y apreciarse en sí misma, ajena a las preocupaciones políticas y sociales. De esta forma:

hasta cierto punto, el hecho de tratar a la música en sus propios términos era un ideal admirable que permitió a muchos oyentes disfrutar de la música por sí misma y como un alivio a los desvelos cotidianos. Pero en otros aspectos, desde su cultivo por parte de la élite económica y social hasta su asociación con los nacionalismos, la música clásica nunca escapó de todo de las redes de la política. ${ }^{19}$

Esta perspectiva se vio en cierta medida reforzada con el desarrollo de la musicología en el siglo XIX, que centró su objeto de estudio en los diferentes estilos y procedimientos musicales del pasado, más que en sus funciones sociales. Fue, en cambio, con el nacimiento de la sociología de

\footnotetext{
${ }^{17}$ Hormigos Ruiz, Música y sociedad, 20-21.

${ }^{18}$ Michèle Dufour, «El idioma romántico de la música absoluta. En torno a Beethoven», en Musyca. Música, sociedad y creatividad artística, coords. Javier Noya, Fernán Val y Martín Pérez (Madrid: Biblioteca Nueva, 2010), 193-209.

${ }^{19}$ Peter Burkholder, Donald Grout y Claude Palisca, Historia de la música occidental (Madrid: Alianza Editorial, 2008), 962.
} 
la música como disciplina (a mediados del siglo XIX), ${ }^{20}$ cuando comenzó a hacerse hincapié en las cuestiones sociales e ideológicas, y es con Theodor Adorno y con su Sociología Dialéctica cuando empiezan a cuestionarse con fuerza y en profundidad los vínculos entre música e ideología.

Todos estos tejidos, no siempre visibles o visibilizados, se entrelazan en los procesos de comunicación musical y de educación musical existentes en la actualidad, debiendo señalar que hasta hoy se sigue perpetuando la idea de "música culta». Igualmente sucede en otros muchos espacios y prácticas, en los que esta noción se une además a la de música como «capital estético». ${ }^{21}$

\section{DISCURSOS PRESENTES EN LA EDUCACIÓN MUSICAL ESCOLAR DE COMIENZOS DEL SIGLO XX EN EL ESCENARIO EUROPEO: UNA APROXIMACIÓN ${ }^{22}$}

La educación musical en Europa estuvo marcada, hasta la llegada del siglo XIX, por las directrices de la Iglesia católica. Monasterios, abadías, capillas catedralicias, colegiatas y santuarios, configuran entonces la infraestructura destinada a la instrucción musical. ${ }^{23}$ Pero, a lo largo del siglo XIX la Iglesia $-\mathrm{y}$ con ella la música religiosa - va perdiendo incidencia en la vida musical y, en este contexto, se fortalece el desarrollo institucional educativo musical privado de mano de una burguesía en ascenso que promueve una «música profana» ligada fundamentalmente a óperas y a teatros. En esta línea, se multiplican las veladas y reuniones musicales en las que se cultivan el baile y la música de salón. Además se consolida la afición a la ópera, se crean coros, sociedades de conciertos, orquestas, conservatorios y acade-

\footnotetext{
${ }^{20}$ Comprendemos la sociología de la música, de acuerdo con los planteamientos de Fubini, como una modalidad de pensamiento estético que se ha venido desarrollando en torno a la música y por la que se entiende «toda forma de pensamiento que pone en relación la música con los hechos sociales»; en Fubini, La estética musical desde la Antigüedad hasta el siglo XX, 407.

${ }^{21}$ Bajo esta conceptualización se entiende la música convertida en algo que podemos almacenar o acumular. La cultura musical es percibida, de este modo, como un proceso de creación, distribución y consumo.

${ }^{22}$ Desarrollamos en este epígrafe un recorrido genérico que, siendo consciente de las múltiples diferencias existentes entre los diversos países europeos, no atenderá con la exhaustividad que merecería a las particularidades que corresponden a cada sistema educativo y a sus respectivas incidencias en los centros educativos escolares.

${ }^{23}$ María Ángeles Sarget Ros, «Perspectiva histórica de la educación musical», Ensayos: Revista de la Facultad de Educación de Albacete, 15, (2000): 117-132.
} 
mias musicales. En este contexto, cada vez más, surgirán en Europa central grupos de aficionados en sociedades para la práctica del canto coral ${ }^{24}$; mientras que la actividad instrumental continuará floreciendo, pero de un modo más lento y limitada a grandes núcleos de población. Hay que hacer notar, de todos modos, que a pesar de toda esta diversidad y multiplicación de iniciativas relacionadas con la música y con la educación musical, la música aún continuará siendo fomentada como una «enseñanza de adorno», sobre todo entre las mujeres. ${ }^{25}$

Además de impulsar mediante el mecenazgo la creación de sociedades, ateneos y liceos destinados a una enseñanza musical que no procura, en todo caso, la formación profesional, la burguesía europea promoverá también la creación de $\operatorname{conservatorios}^{26}$ : la gradual configuración de la música como objeto de ostentación entre las clases altas lleva a un creciente interés por acceder al conocimiento y a la profesionalización musical por parte de los segmentos más acomodados de la sociedad.

En este clima y con el incipiente desarrollo de los sistemas educativos nacionales, la música comienza a establecerse como materia escolar en diferentes países europeos, particularmente en aquellos de confesión religiosa protestante. Su presencia en el currículum se garantiza debido a diversas razones ${ }^{27}$ : la incorporación del lenguaje musical procura incidir en el perfeccionamiento del canto litúrgico del pueblo; ${ }^{28}$ se asocia la edu-

\footnotetext{
${ }^{24}$ El movimiento coral se desarrolló tardíamente en España, donde las primeras sociedades corales surgen en Barcelona en los años cincuenta del siglo XIX, de mano de Josep Anselm Clavé y Juan Tolosa.

${ }^{25}$ Hecho que contribuirá a la pervivencia de marcados sesgos de género aún latentes a día de hoy. Atendiendo a aspectos relacionados con esta cuestión, anotamos los trabajos de Lucy Green, Música, género y educación (Madrid: Morata, 2001), también de Lamb, Dolloff y Howe, «Feminism, Feminist Research and Gender Research in Music Education», en The new handbook of research for music teaching and learning, eds. Colwell y Richardson (New York: Oxford University Press, 2002), 648-674, o de María Loizaga Cano, «Los estudios de Género en la Educación Musical», Revisión Crítica. Musiker, 14, (2005): 159-172; Patricia Digón Regueiro, «Género y música». Música y Educación: Revista trimestral de pedagogía musical 13 (41), (2000): 29-54.

${ }^{26}$ Los primeros conservatorios datan su origen en la Italia del siglo XVI, pero no será hasta tres siglos más tarde cuando comiencen a adquirir una notable dimensión europea. El primer conservatorio de España se funda en Madrid en el año 1830.

${ }^{27}$ Susana Flores, «Sociedad, cultura y educación musical», en Música, complementos de formación disciplinar, coord. Andrea Giráldez (Barcelona: Graó, 2010), 9-34.

${ }^{28}$ A modo de ejemplo, puede señalarse como en las escuelas elementales rusas la práctica de los cantos litúrgicos se constituyó como elemento del currículo tras la legislación de 1819. Alude Flores (2010) a que líderes religiosos de países como Inglaterra, Dinamarca, Noruega y Suecia, destacaban
} 
cación musical al fortalecimiento de la moral y a la mejora de la conducta social ${ }^{29}$; se considera que el aprendizaje musical facilita aprendizajes de otras áreas de conocimiento y de conducta ${ }^{30}$; se valora la música como forma de preservar la herencia cultural y de promover el sentimiento de pertenencia e identidad nacional ${ }^{31}$; y se aprecia también la formación musical por su posible contribución a la autoexpresión y al desarrollo individual. ${ }^{32}$

Con todo, las diferencias entre los diversos contextos son muchas y, en el escenario español, portugués e italiano, la implantación de la enseñanza musical continúa siendo escasa en este tiempo. Por otra parte, un currículum excesivamente tecnificado, centrado prioritariamente en el aprendizaje de la lectoescritura musical llevó a la convicción, a finales del siglo XIX, de la necesidad de cambiar objetivos, contenidos y métodos en las aulas de música.

Será a comienzos del siglo Xx cuando los avances que se vienen desarrollando en torno al estudio de la infancia y la afirmación de la filosofía educativa de la Escuela Nueva, en medio de distintos cambios sociales y culturales, contribuyen a generar un clima de renovación pedagógica que se extiende al campo musical. Asistimos pues, desde los albores del siglo, a la extensión de la idea de renovación y de investigación en la educación musical, ${ }^{33}$ lo que se pone de relieve en este momento con la aparición de múltiples sistemas de educación musical dirigidos a la educación general, que se fundamentan en las directrices de la nueva pedagogía.

De este modo, las propuestas pedagógicas del belga Ovidio Decroly y de la italiana María Montessori trasladan también sus influencias a los

con frecuencia la necesidad de las clases de canto en la escuela como modo para lograr mejoras en la participación de la congregación en el canto del culto religioso.

${ }^{29}$ El inglés John Turner explica, en su Manual of Instruction in Vocal Music (1833), los rudimentos de la música como forma de ayudar al pueblo a practicar la música eclesiástica, además de promoverla como una alternativa «saludable» para el goce del tiempo libre por parte de las clases trabajadoras.

${ }^{30}$ Podemos hacer referencia a la existencia de variados manuales y textos como Wilhelm Meisters Wanderjahre (1821-1829) de Goethe, donde se defiende el estudio de la música como forma de cultivar la conciencia moral y modo de mejorar las habilidades de escritura y de cálculo.

${ }^{31}$ Noción muy extendida en la historia contemporánea, fundamentalmente a través del aprendizaje de himnos nacionales y patrióticos.

${ }^{32}$ Esta idea, argumentada por Comenius y Rousseau, tuvo continuidad en el pensamiento de Pestalozzi y de Froebel.

${ }^{33}$ María José Valles del Pozo, «La educación musical en la historia de occidente: Apuntes para la reflexión», Neuma: Revista de Música y Docencia Musical, 1, (2009): 218-232. 
procesos de enseñanza y aprendizaje musical, que empiezan a caminar hacia la búsqueda de lenguajes más activos, creativos y participativos. Así, comenzarán a percibirse cambios en la enseñanza musical escolar que emanan de las innovaciones propuestas fundamentalmente por el suizo Jaques Dalcroze, con sus métodos de educación musical activa que combinan la rítmica con la dinámica corporal; por el húngaro Zoltan Kodaly, que propone centrarse en el ritmo, la audición interior y la entonación utilizando materiales procedentes del folklore tradicional; por el alemán Carl Orff, creador de los instrumentos que hoy conocemos precisamente como «instrumentos Orff»; o por los franceses Maurice Martenot y Edgar Willems, entre otros, dejando sentir sus influencias en el contexto peninsular, aunque solo perceptibles en entornos que podríamos considerar socialmente elitistas.

Estos nuevos métodos de enseñanza musical entroncan con las directrices de la nueva pedagogía, pues la formación integral del niño como ser humano pasa a ser, así mismo, el objeto de la música, con la pretensión de desarrollar mejores personas y ciudadanos del futuro. De este modo, se otorga al alumnado un papel activo en la educación, concediendo prioridad a su experiencia y participación en el aprendizaje de la música; se defiende una educación musical para todas las personas, por tanto, no sólo basada en una supuesta existencia de cualidades especiales; se argumenta la importancia de la iniciación musical en el ambiente familiar y en la primera infancia; se propone una enseñanza global de la música, en todos sus elementos: rítmico, melódico y armónico en la expresión vocal, instrumental y corporal, y el material musical con el que se trabaja procede fundamentalmente de la considerada «música culta» occidental y del folclore.

Así pues, todas las innovaciones introducidas por los citados y reconocidos pedagogos musicales, en el denominado "siglo de la Iniciación Musical» o "siglo de los grandes métodos», ${ }^{34}$ tuvieron repercusiones notables en los modos de hacer, es decir, en las metodologías utilizadas por maestras y maestros - con una muy desigual incidencia en los diferentes contextos, si nos referimos a Europa-, pero no tanto en los contenidos y discursos subyacentes, advirtiéndonos esto acerca del peso de las anteriores y pasadas tradiciones musicales.

\footnotetext{
${ }^{34}$ Violeta Hemsy de Gainza, «La educación musical en el siglo xx», Revista musical chilena, 58 (201),
} (2004): 74-81. 
Podemos decir que la extensión cada vez mayor de una «cultura musical» a la población, antes restringida a unos reducidos segmentos sociales, caminó de la mano de los avances en los sistemas de educación, de la extensión de la enseñanza musical a múltiples espacios, de la creciente programación y realización de conciertos para niños y niñas, así como de otros progresos de tipo técnico y relacionados con los medios de comunicación, tales como la utilización del gramófono o de la radio. Con esta ascendente divulgación musical surgieron nuevas demandas y necesidades educativas, aunque igualmente hemos de resaltar que continuaron preservándose —en muchos casos y no siempre de forma evidente- viejos discursos asentados en representaciones pasadas, tales como aquellas que otorgan valores diferentes a la música popular y a la música culta, como en otros términos tuvo ocasión de señalar Costa Rico:

[la] pervivencia de códigos como tradiciones discursivas (explícitas o no) que encauzan la producción, la reproducción y la legitimación del conocimiento escolar [...], llega a ser uno de los elementos nucleares de la dialéctica entre la continuidad y el cambio, e incide sobremanera en la misma pervivencia temporal y contextual de los modelos pedagógicos. ${ }^{35}$

A este respecto alude Cook a que la "música culta» continuó ocupando un lugar preeminente en el currículum escolar. No en vano señala que:

esta distinción entre gran arte y arte menor persiste aún en el formato habitual de los libros de texto de historia de la música o de apreciación musical. Cuentan la historia de la música «culta» occidental, centrada inicialmente en Europa y expandiéndose en el siglo XIX a Norteamérica. Y después, cuando la historia está en esencia concluida, añaden un capítulo o dos sobre música popular. ${ }^{36}$

\footnotetext{
${ }^{35}$ Antón Costa Rico, «Modelos pedagóxicos, códigos curriculares e sociedades en perspectiva histórica», en A Educação Escolar em Perspectiva Històrica, org. Blanck Miguel e Teixeira Corrêa (Brasil: Autores Asociados, 2005): 7-78 (12).

${ }^{36}$ Cook, De Madonna al Canto Gregoriano, 71.
} 


\section{ENTRE LA «MÚSICA CULTA»Y LA «CULTURA MUSICAL»: PERFILANDO NUEVOS HORIZONTES EN LA EDUCACIÓN MUSICAL ESCOLAR}

Tanto la filosofía y la estética musical como la sociología de la música han destinado variados estudios a la indagación y delimitación entre las fronteras de lo considerado «música culta» y "otras músicas», pero aún hoy encontramos que esta diferenciación se perpetúa, pues «la distinción entre culto y popular va mucho más allá del mundo estrictamente sonoro. De hecho son contenidos sociales que hayan su expresión en el ámbito musical, como los encontramos asimismo en muchos otros ámbitos de la cultura». ${ }^{37}$ Reflexionar en torno a los usos del concepto «música culta» - o bien "música artística» o "música seria, como en otras ocasiones se ha denominado- y sobre cómo dicho constructo se introduce en los discursos, representaciones y contenidos de las clases de música, más allá de las metodologías utilizadas, requiere asumir que «la música — cualquier tipo de música- es portadora de mensajes, a pesar de que no siempre vaya acompañada de palabras. Y con ello, la música no es tan solo estética, sino que también es ética». ${ }^{38}$

Probablemente hoy conviene que la educación musical nos proporcione herramientas para apreciar la música en su dimensión estética, brindándonos posibilidades para adentrarnos en sus aspectos formales y estilísticos. Pero también, y sobre todo, en su dimensión ética, histórica y social, atendiendo a los usos, los significados y las funciones que ha cumplido y cumple en las distintas sociedades. De este modo, se hace necesario formar en una perspectiva crítica que rompa con los estereotipos y hegemonías que no sólo son de clase social, sino también de género, entre otros. Esto podría llevarnos a hablar de educar en y para una cultura musical en lugar de educar merced a las fronteras de una «música culta», hoy paradigmáticas e inapropiadas.

En este sentido ha señalado Blacking que «las divisiones al uso entre música culta y música popular son inadecuadas. Carecen de sentido y precisión como indicadores de diferencias musicales». ${ }^{39}$ Así, cabe am-

\footnotetext{
${ }^{37}$ Hormigos Ruiz, Música y sociedad, 95.

38 Josep Martí, Más allá del arte. La música como generadora de realidades sociales (Barcelona: Deriva, 2000), 13.

39 John Blacking, ¿Hay música en el hombre? (Madrid: Alianza, 2006), 31.
} 
pliar todo horizonte de cultura musical, superando los límites y sus consecuentes limitaciones, pues

con imperturbable y eficaz torpeza los utiliza la industria cultural, haciéndolos pasar por verdaderos y dibujando sobre ellos una división de mercados que ya ha revelado para sí una feliz funcionalidad. En cuanto al público, se adecua de buen grado, amparado por un sistema que proporciona a sus necesidades un orden útil, en nada diferente al ya experimentado en las agradables visitas a los supermercados. ${ }^{40}$

La trayectoria de la educación musical escolar en Europa ha situado a la disciplina en un lugar relativamente aceptable, con desigual situación en los distintos países. ${ }^{41}$ Nos situamos en un contexto en el que la música forma parte de los currículos escolares oficiales. Buena parte de las cátedras universitarias de música desarrollan estudios dedicados a la pedagogía musical, numerosos y variados proyectos dentro y fuera de la escuela han consolidado la importancia de la educación musical en diferentes contextos, se desarrollan investigaciones de relevancia e interés para el área, las vías de intercambio científico son cada vez más accesibles, se cuenta con métodos y recursos adecuados y adaptados a diversas necesidades, entre otras cuestiones. No obstante, la inmediatez de la práctica profesional educativa nos lleva generalmente a centrarnos exclusivamente en la actividad cotidiana, sin reflexionar en torno a las experiencias pasadas y, por lo tanto, en relación a los posibles cambios y continuidades existentes. Porque conocer la trayectoria - también social y filosófica- de las disciplinas y el análisis de los conceptos es importante para comprender la situación actual y dotarnos de herramientas que nos permitan cambiarla, tal como a lo largo de la última década han puesto de manifiesto diversos estudios e investigaciones internacionales y españolas en el ámbito de la historia del currículum. A este respecto, valoramos que sigue existiendo un desconocimiento en relación a los significados de la educación musical, con la consecuente falta de valoración de la materia en los ámbitos escolares y académicos. Además, continúa

\footnotetext{
${ }^{40}$ Baricco, El alma de Hegel y las vacas de Wisconsin, 17.

${ }^{41}$ Particularmente, en el caso del territorio peninsular, aún quedaría mucho camino por recorrer y los últimos cambios en legislación educativa no contribuyen precisamente a la incorporación efectiva de mejoras, más bien al paulatino desmantelamiento y deturpación del área.
} 
presente el debate sobre la idoneidad de la «música culta» para aprender música.

Consideramos que actualmente es necesario aceptar la diversidad y multiplicidad musical como realidad inherente a nuestro tiempo, en un momento en el que «la música está por doquier, es omnipresente. Su espacio natural no se limita ni mucho menos a las convencionales salas de conciertos. Su presencia invade nuestras casas, los largos corredores del metro, el interior de nuestro automóvil, las iglesias, los grandes almacenes...». ${ }^{42} \mathrm{Y}$, sin embargo, nunca pasó tan desapercibida. Para ello cabría abordarla sin reservas desde los diversos ámbitos educativos, atendiendo a conceptos significativos en la cultura actual, como por ejemplo el de relevancia (o impacto) social. Creemos importante entonces indagar en el conocimiento profundo de los contextos educativos, desarrollar estrategias de adecuación metodológica y aplicar recursos en función de estos, así como de las características de los destinatarios y de sus necesidades. Comprender música requiere no solo saber escucharla o saber leerla —en lo que a su notación se refiere-, sino profundizar en las circunstancias en las que nació, se desarrolló y se utiliza, para poder así articular argumentos críticos que nos permitan escuchar y escoger conscientemente.

\section{Nota sobre la autora:}

María Eugenia Bolaño Amigo es licenciada en Pedagogía por la Universidad de Santiago de Compostela (USC, 2012), graduada por el Conservatorio Profesional de Música de la misma ciudad (2011) y titulada en Música por el Conservatorio Superior de Música de Vigo (2016). Cursó el Máster de Investigación en Educación, Diversidad Cultural y Desarrollo Comunitario en la USC (2013), siendo becaria de colaboración del Ministerio de Educación y Ciencia en el Departamento de Teoría de la Educación, Historia de la Educación y Pedagogía Social. Actualmente realiza su tesis doctoral en el marco del Programa de Doctorado en Educación ofrecido por la USC bajo la dirección del profesor Antón Costa Rico y de la profesora María del Mar del Pozo Andrés. Está vinculada al Grupo de Investi-

\footnotetext{
${ }^{42}$ Martí, Más allá del arte, 13.
} 
gación en Pedagogía Social y Educación Ambiental (SEPA-interea) desde octubre del año 2014 en calidad de Técnica Superior de Apoyo a la Investigación. Sus líneas de investigación giran en torno a la historia de la educación contemporánea. 